\title{
The Polyfurcation Century: \\ Does the Evolution on Earth Have a Cosmological Relevance?
}

\author{
Akop P. Nazaretyan \\ Institute of Oriental Studies, Russian Academy of Sciences
}

Dedication: To the bright memory of my dear friend and colleague, Cynthia Brown, who helped me a lot in completing this paper.

\begin{abstract}
Special cross-disciplinary research and respective calculations done independently by scientists from various countries have shown that the 21 st century is expected to be crucial for the human history. Current generations' activities will determine what exactly the turning point will look like and what direction the subsequent evolution will go. Modern physicists and specialists in heuristics are advancing strong reasons for the conclusion that there is no absolute ban on the range of purposeful mass-energy control and therefore, mind's cosmic-scale influence is potentially unlimited. Yet, the range of available intellectual self-control to escape destructive effects is under issue so far. How long can the technological power growth be reliably balanced by the advancing behavior-regulation qualities? From time immemorial, the relative sustainability of human communities (from primitive tribes to nations, social classes or world confessions) has been provided by the image of a common enemy. Inter-group conflicts have been abridging in-group violence and with it, have been setting the vector for the construction of life's meanings. Yet, the current level of technological development completed by blurring lines both between war and non-war technologies and between the conditions of peace and war has made this psychological inertia suicidal. So the problem of life's meanings is becoming the nucleus of the 21 st century global problems: Will the human mind prove ready to develop strategic meanings beyond religious or quasi-religious ideologies which are always built on the "them-us" mental matrix? Insights of great philosophers and prophets, as well as special socio-psychological experiments and some crucial episodes in political history have demonstrated that besides the image of a common enemy, both human solidarity and strategic meanings can be built on the image of a common cause (not aimed at an enemy agent), although the experience of assimilating this kind of construct by the mass consciousness is scanty. Instead, historical evidence is abundant showing that after long periods without real or potential wars, life's meanings dilute and the masses feel nostalgia for new demons. Actually, we observe an intensification of this trend in many regions of our planet accompanied by a growing instability in global geopolitics. An international educational program designed to develop cosmopolitan worldviews free from group-versus-group attachments is suggested in the paper.
\end{abstract}

Keywords: prognostication, non-linearity, menace, danger, risk, singularity, scenarios, violence, technohumanitarian balance, ideology, life's meaning.

In fact, the people living today are the most important ever to walk the surface of the planet, since they will determine whether we attain this goal or descend into chaos.

Mitio Kaku

The need is clear. The outcome is not. Lowell Gustafson 


\section{To Start With: Comments on Methodology}

Generals are always prepared to fight the last war.

Winston Churchill

In 2016, the Nobel Peace Institute held an international academic discussion on the mechanisms of violence, war and peace (see [1] and others).

Most participants came to the conclusion that sharpening tensions in current political relations made a new world war inevitable in the 21 st century. It is worth mentioning that the "world war" concept clearly reminded images from either the first or the second halves of the 20th century (which had been essentially different), and afterwards, in February 2017, the Swedish government re-introduced the army draft, which had been canceled seven years earlier.

This looks like the effect that sociologist Robert Merton called a self-fulfilling prophesy [2, p.477]. Later, an additional term self-NON-fulfilling prophesy emerged in the relevant literature. It implies that an opportune warning can help an escape from unfavorable developments or, inversely, an excessive confidence in one's coming success can interfere with the expected achievement. I will show, below, that the quality of projections and people's attitude to them has become a challenge to world civilization's destiny...

In December 2016, the Global Challenges Foundation in Stockholm invited me to write an analytical paper on the challenges that humanity faces in the 21 st century. The invitation was willingly accepted, as my many years' experience in political psychology and system forecasting helps select points of importance in the continuing discussion. A journal version of the paper is offered here for readers.

Historical experience in social prognostication shows that the major cause of errors has been authors' propensity to linear extrapolations, which is consonant to hard determinism in classical science. Post-classic science has essentially changed attitudes to the concepts related to chance and nonlinearity and respectively, to the role of mental factors in the course of events. Modern methods are synthesized in synergetic (complexity theory) patterns, so far as they emphasize the instability phases and palliative scenarios and always mention the price for progress in any crisis solution; thus human thinking and will are involved in global causalities. Nevertheless, the scope of subjective influences is disputable, so that even though a model looks formally nonlinear (with exponential curves, etc.) the nonlinearity gradient, if underestimated, entails blunders.

The underestimated subsequent deflections from a linear model are in turn conditioned by two circumstances. First, by the short retrospective distance to be extrapolated, i.e. the most apparent current trend is transferred into an indefinite future. Second, by the insufficiently system oriented property of the analytic model: the extrapolation is inferred from separate fields like economy, power industry, demography, ecology and so on. This smoothes the "subjective" factors and causes inadequate appreciation of the actual opportunities and challenges. Meanwhile, comparative historical research shows that the specific weight of mental reality in the systemic causalities has been progressively growing and has achieved a very high magnitude.

"Challenge" in modern psychology of social security is a complex concept composed of three variables: menace, danger and risk [3]. Menace is any event that can damage the agent's interests. A living organism, even more a human individual or a society, permanently exist in the condition of outer and inner menaces which don't produce dramatic effects until the agent successfully copes with them. Danger is a more delicate variable: it is described as a relation of the menace to the agent's readiness to withstand it. Finally, risk is the probability of danger increasing in case of either certain activities or inaction.

Lowered menaces can provoke growing dangers in certain situations and vice-versa. A textbook 
example: whereas there are considerably more menaces outside one's place of residence, accidents and injuries (up to sudden deaths and killings) are more frequent at home. Having left the dwelling, one remembers about probable menaces, is more concentrated and ready to face them, while back at home, he/she relaxes and thus runs into unexpected troubles. Danger essentially increases in two cases: if one ignores, underestimates or neglects the menace and, on the contrary, if "the rabbit's attitude" entails the feeling of doom and one's own helplessness.

These definitions especially matter when we discuss the planetary outlook. With that, a predicting value essentially depends on how much the trends picked for extrapolation correspond to the prognostication scale and tasks. The actual historical situation is such that effective patterns of the future require a maximal retrospective distance and the systematic involvement of disciplinary fields from cosmology to psychology. This is now available in view of the fundamental scientific discoveries of the latest decades, which give us a new background to estimate the planet's observable futures.

\section{Mega-History: A Cross-}

\section{Disciplinary Research Project}

...By now, this is the most complete knowledge about you and me, about why we do exist and why we are so as we are,

about what might follow us and to what extent this depends on each one. Yakiv Osvitleny

An empirical data array had been accumulated by the 1980 s to argue

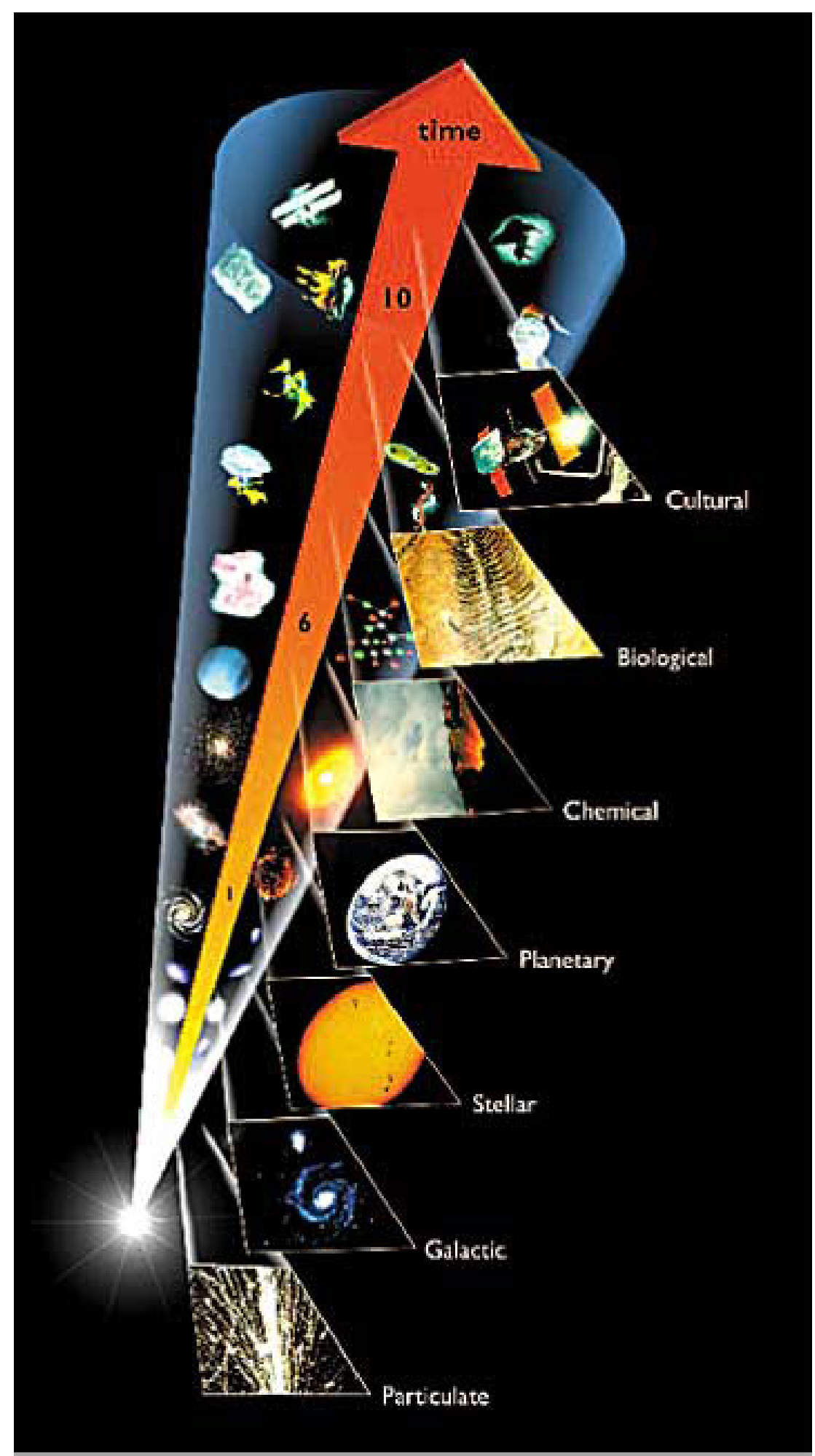

Fig. 1. The Stages of Cosmic Evolution (by Eric Chaisson) 
that social history, prehistory and the histories of biosphere, Earth's crust and cosmos were a single process. We could distinctly trace back common vectors of the consecutive transformations over a period of almost 14 billion years, to the very horizon of actually available retrospection, the "Big Bang". The Metagalaxy has been successively evolving towards more and more complex and sustainable farfrom-equilibrium conditions. Scientists from various countries and fields began to speak about a universal evolution, and a research project appeared aimed at an integrated image of the past, variously called Mega-History, Big history (see [3-13] and others).

The mega-trend of increasing complexity apparently contradicts the suggestions inferred from the classical natural history (time as growing entropy; heat death theory), but it is reliably corroborated by the empirical data in modern sciences and humanities; therefore, astrophysicists have to distinguish between the thermodynamic arrow of time and the cosmological arrow of time (see Fig.1) leaving under issue their causal relations.

The arrow looks rectilinear on Fig. 1 yet the cumulative changes have not, in fact, been uniform. The first billions of years after the Big Bang, evolution had been slowing down until heavy elements were synthesized in the depths of first generation stars and ejected into the cosmic space by supernova explosions. This initiated an additional self-organization mechanism with competition for free energy (heavy elements unlike light ones need energy from outside). Thus about 10 billion years ago, as evolution went on its way towards organic molecules and living matter, the slowdown changed into acceleration: "the two hoses" of the universal evolution (see Fig.2).

The Solar system emerged nearly 4.6 billion years ago, and the first signs of living organisms on Earth are recorded since about 4 billion years ago. Recent discoveries in paleontology, biophysics and cosmology have reinforced the hypothesis of life's cosmic origin: the first organisms supposedly

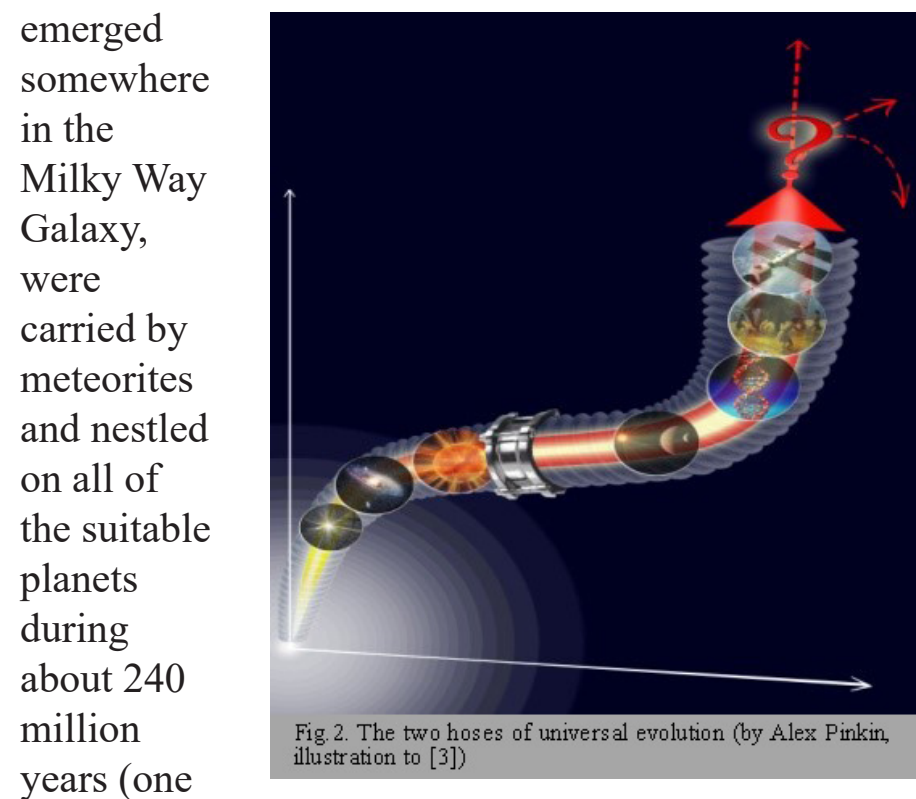

Galactic year). In particular, their first signs on Earth precede the appearance of the oceans $[14,15]$. Some astrophysicists argue that highly intensive meteorite activity on the early stage of Solar System formation more than once brought primitive organisms to the Earth crust, but each time they were destroyed by the same bombing process. Life finally nestled only after the bombing had relatively reduced [16].

Anyhow, our planet was likely one of multiple points on which further cosmic evolution was localized. The important thing here is that the acceleration continued and followed an astonishingly regular regime. A series of independent calculations done by Australian, Russian and American scientists, who used different sources and even different mathematical instruments, show that the time periods between phase transitions in biospheric, pre-social and social evolution have been shortening in a simple logarithmic fashion for 4 billion years [15, 17-19] (see Fig.3).

These calculations disavowed the "exogenous" approach to explain the catastrophes and crucial episodes in both social and biospheric histories, in which analysts search for external causes like geologic, climatic or cosmic cataclysms, although this each time required artificial assumptions. In the 

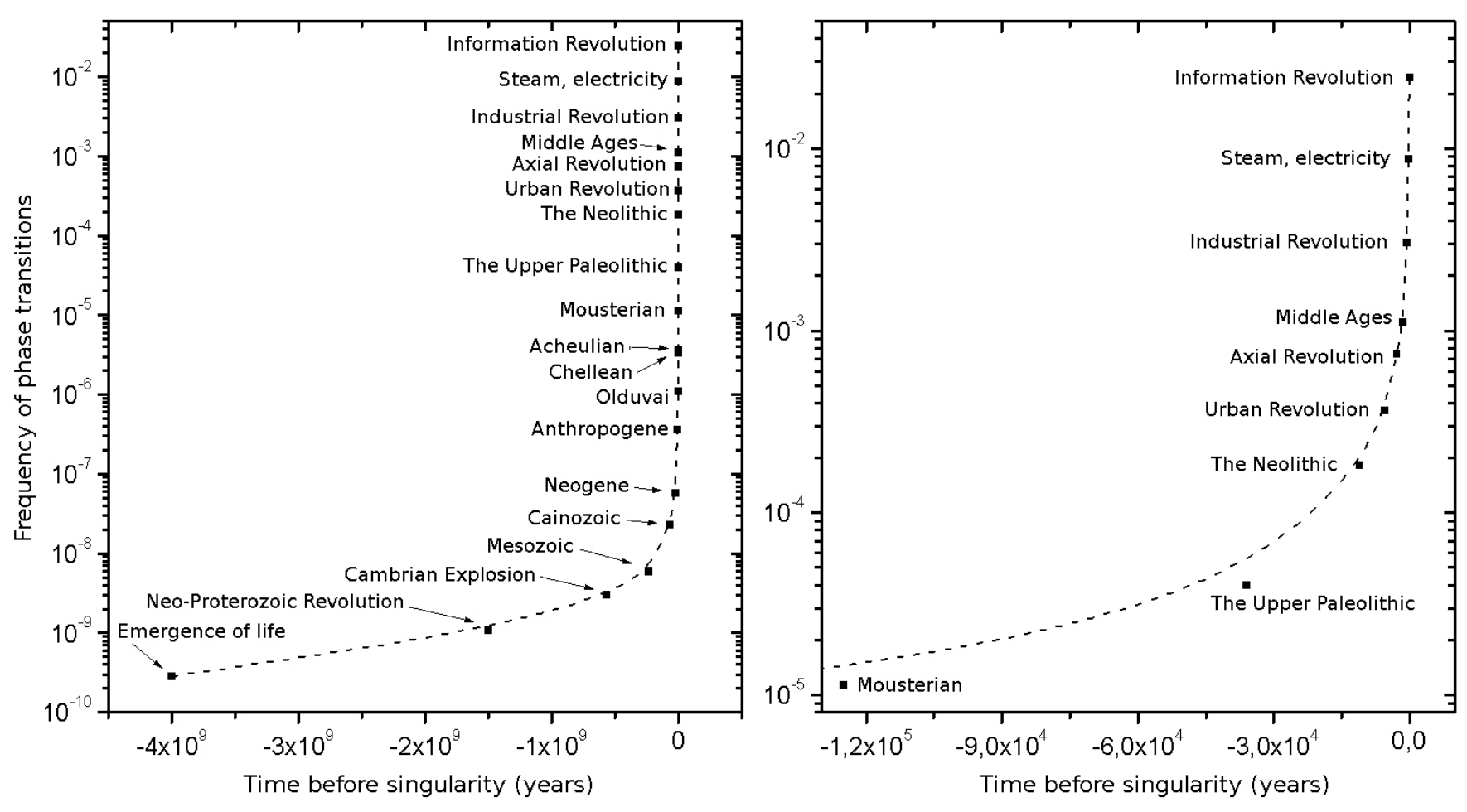

Fig.3. Scaling law in the phase transitions (by Alexander Panov [16]).

new version, the story looks different. Continents have been drifting, magnetic poles shifting, big meteorites falling down, powerful volcanoes erupting and climate repeatedly changing during the 4 billion years; later on, the wayward Homo sapiens intervened with their "free will" and never-ending extravagances, and about 10 thousand years ago (the Neolithic) the anthroposphere started to arise; nonetheless, the global transitions each time preceded by crises and catastrophes followed the logarithmic succession.

This paradoxical fact turns us to the synergetic pattern of delayed dysfunction [3]. The accumulation of negative effects of a sustainable non-equilibrium system's (biosphere and, later, society) antientropy activity entails, over time, environmental degradations which devalue the old mechanisms of sustainability and extensive development. Thus the outdated mechanisms provoke a catastrophic entropy growth, so that the system's subsequent viability requires more delicate mechanisms and advanced "intelligence". The global crises caused by the biosphere's or society's own activities have been each time solved by means of deep reconstructions and archaic subsystems' cutoff, like extinction of species and the destruction of social-natural entities.

Careful analysis of the crucial episodes shows that, over and over again, the events could have developed otherwise. The evolution of biosphere and later anthroposphere could have collapsed in a global catastrophe (the simple attractor, in synergetic terms) or have been suspended (the horizontal attractor) and slowly degraded with time. Yet, we live on this planet thanks to the fact that evolution has moved towards the vertical attractors in each turning point, that is, global sustainability has been each time reestablished by means of the explosive growth in the global system's complexity and its aggregate intellectual quality; this cost catastrophes of many separate subsystems, but it ensured new global sustainability 
on a higher and higher level of non-equilibrium. One more consideration originates from the General System Theory's implementation principle: all possible events do happen. From that, we must assume that alternative scenarios are performed in multiple points of the Universe and very few of the evolving planets achieve a level comparable to the one we find on Earth [3].

\section{The Singularity Puzzle}

The ever-accelerating progress of technology and changes in mode of human life... give an appearance of approaching some essential singularity in the history of the race beyond which human affairs, as we know them, could not continue. John von Neumann

Having extrapolated the hyperbolic curve into the future, the researchers have come to a nearly unanimous (ignoring the individual interpretations) and even more striking result: around the mid 21st century, the hyperbole turns into a vertical. That is, the speed of the evolutionary processes tends to infinity, and the time intervals between new phase transitions vanish. The point on which the value of a function becomes infinite is called the singularity; therefore, the mentioned mathematical inference has been designated by the authors' names as Snooks Panov's Vertical or Kurzweil's Singularity [20, 21].

The Mega-history inferences are corroborated by the calculations based on more particular parameters, like the accumulation of the genetic burden because of falling children's mortality and growing longevities, etc. Indeed, our civilization seems to be approaching at a growing rate the polyfurcation point whose planetary (and cosmic?) significance exceeds all the foregoing phase transitions. Thus, the fourbillion-year-long evolution intrigue will be solved somehow or other during the current century. Crossdisciplinary investigations applying a synergetic pattern help discern three attractors beyond the mathematical Singularity, with a set of scenarios within each one.

1. Transition to history's "descending branch". European philosophers wrote a lot about this perspective in the 18th-19th centuries; yet they saw external reasons (like Earth aging or the Sun blowing out) and used to put this transition off many thousands, millions or hundreds of millions years in future. Now we see that the cause of history exhaustion can be exclusively humans' own activity and that the timetable amounts to decades. As we trace onward various anthroposphere and biosphere degradation scenarios we find that the process can continue from several days to millennia; anyhow, the simple attractor is that Earth will become a "normal" cosmic body like the Moon or Mars free from res cogitans and living matter at all.

2. Evolution's suspension guaranteed by a shift of core social activity to virtual reality - horizontal attractor. The "hang-up" may be long-term, but sooner or later, the escapist civilization will be absorbed by the growing universal entropy.

3. Transition from evolution's planetary phase to the cosmic one. This doesn't look idyllic either, since the cosmically relevant phase implies radical transformations in the mind's conditions, qualities and substrates (like manmachine structures and so on) as a premise for subsequent development: progress has never been the way "from the worse to the better" but just an alternative to the system's destruction.

\section{Is a Cosmic Perspective Possible?}

Probably, the "Silence of Cosmos" simply means that not a single planetary evolution has so far given birth to intelligence commensurate to its cosmic destination. Vazgen Garun 
Up to the end of the 20th century, most of respectable astrophysicists shared the belief that life, society, culture and mind were nothing but epiphenomena (side products) of material structures' blind game, without any potential influence on cosmic developments and doomed to dissolve in the ruthless universal entropy. The Nobel Prize winner, Steven Weinberg [22], expressed this common belief by noting that only the awareness of the unavoidable end imparts a color of a "high tragedy" to the "farce" of human existence. Moreover, according to the extreme version, what we call evolution is in fact an irreversible entropy growth in the Universe and humankind with its crazy ambitions is the "cosmic trash". Some Soviet astrophysicists or descendents from the USSR influenced by the "Russian Cosmic Philosophy" ventured to assume humans' potential intervention in the cosmic-scale processes and strategic perspectives; yet this was rather an exotic position in the 20th century science.

Following relevant papers from the late 1990s on, we can see that the conceptual mainstream has considerably changed. Abundant arguments for the assertion that consciousness is not a side product, but a "cosmologically fundamental fact" and it can conclusively influence subsequent evolution of the Metagalaxy, are widespread in recent astrophysical books and articles outside Russia (see [23-26] and others). The authors argue that no "physical laws" impose an absolute ban on creative engineering. Even before, studies in gestalt-psychology and heuristics had demonstrated that any boundaries were creatively surmountable by a change of the cognitive meta-system [27]. Specifically, those parameters of the problem situation that are uncontrollable constants inside a certain model become manageable variables within a more complex meta-model; this implies that both the range and scale of purposeful control of mass-energy flows are potentially unlimited.

Yet, if this is so, cosmos should be full of powerful civilizations! With up-to-date high tech, astronomers discover on average weekly a couple of new planets outside Solar system and several ones rather similar to Earth by their parameters have been lately found. However, all efforts to register a slightest intelligent activity sign remain fruitless. Thus the so-called Fermi Paradox ("Where are they?"), which was worded by the Italian physicist in the early 1950 s (see in [28]) sounds more and more actual.

\section{Technology, Psychology and Social Viability: The Law of Techno- Humanitarian Balance}

\author{
We have created a Star Wars civilization, \\ with Stone Age emotions, medieval \\ institutions, and godlike technology.
}

Edward Wilson

To explain the paradox, the scientists referred to technical and conceptual troubles, but lately the "humanitarian" side has gotten growing attention. Summarizing diverse data from cultural anthropology, history, historical sociology and psychology concerning anthropogenic catastrophes, researchers have found a regular relation among three variables: technological potential, quality of cultural control (actual values and norms) and social sustainability: the law of technohumanitarian balance. Namely, the higher is the power of production and war technologies, the more advanced behavior-regulation is required to enable self-preservation of the society [3,21]. As soon as mind achieves power which is not compensated by adequate aggression-retention, it becomes destructive and in the short run, self-destructive for the society.

Each new technology (not only military) carries new menaces that entail catastrophes; their danger declines after social psychology and culture have adjusted to them. As special investigations show, many flourishing societies' tragic destiny was due to the unreadiness to cope with their own increased power, so that the natural or geopolitical backgrounds of their existence were subverted. History was 
continued by those who managed to balance their values and norms of activity with the new technologies within the proper time, and the selection of viable social organisms was intensified by global anthropogenic crises. The dramatic "scrapping" of imbalanced societies has entailed important positive consequences as well: while both the destructive power of technologies and the demographic densities have been increasing, the societies' Bloodshed Ratio (the ratio of the average number of killings per unit of time to a population size) has been nonlinearly but successively falling down. This paradoxical fact was first demonstrated with figures by the German sociologist of Jewish origin Norbert Elias (who had lost his relatives in the Holocaust and managed to escape from his motherland) in the late 1930s [29] and later confirmed by new independent anthropological, sociological and psychological researches [30-36].

Thanks to this historical trend, humanity in a whole, unlike many regional communities, has so far managed to rain in the increasing power of its tools. Yet, having accepted potentially unlimited capabilities of the technological intelligence, we are not ready to estimate confidently the perspective of its humanitarian constituent. What can play a fatal role in the destiny of Earth or any other planetary civilization are the incommensurable ranges of self-control - aggression-restraint and sublimation - and the natural power manipulation. Finally, any intelligence originated in a planetary evolution fails to restore its inner balances and destroys itself before it achieves the cosmically relevant stage. At best, we can suggest that very few technologically developed civilizations (perhaps, a single one) prove able to overcome the borderline between planetary and cosmic stages. The rest, as well as the biospheres that interrupt their evolution at earlier stages, remain universal evolution's waste products by implementing all of the deadlock strategies in universal natural selection. Will Earth civilization be among them?

\section{Peace and War: The Diffusing Criteria}

This is the way the world ends, Not with a bang but a whimper.

Thomas Stearns Eliot

The "global crises" concept dates back to the 1950s; humanity was then on the brink of a nuclear war. Thanks to a series of unprecedented international compromises in the 1960 s, a brittle military and political equilibrium was settled; psychological adjustment to the nuclear menace restricted the danger of a total catastrophe. Yet the shock experience which supplemented the tragedies of the two world wars increased awareness of planetary interdependencies, on the one hand, and anxiety about the future, on the other. Since the early 1970s, the attention of scientists and the public was reoriented on expected global risks. The unparalleled and geographically unequal demographic growth, the coming exhaustion of energy, sweet water and atmospheric oxygen and the other causes of apprehension became issues for passionate discussions.

The debates concerning current and predicted menaces essentially influenced politicians and the public and favored the satisfactory completion of the 20th century. Panhuman success was due to the fact that the main menaces had been discovered and overcome in proper time. New generations have not yet fully appreciated the greatest achievements like the mutual non-use of nuclear weapon, the ban on nuclear tests in atmosphere, hydrosphere and cosmos, and the global ecological measures. These were unprecedented breakthroughs, which have made possible our current existence. For the first time in human history, a new kind of non-confrontational political coalitions emerged, which were not aimed against an enemy agent, but cemented by a faceless (free from a subject for common hatred) threat of total collapse. This was the way human culture and psychology were adjusting to nuclear technologies, like long before they had adjusted to firearms, iron 
weapons, and so on back to the primary choppers by which Homo habilis used to crush one another's skulls 2.5 million years ago.

Nowadays, most papers on global prognostication either design an unconditioned and cloudless progress or turn us back to the late century conflicts (a recent brilliant example is mentioned in the beginning of this paper). Meanwhile, as we compare up-to-date global problems to large-scale historical precedents and analyze advanced scientific projects, we find reason to suggest that most of expected threats are potentially surmountable by means of "exponential technologies". This refers both to demographic growth, energy and other resources exhaustion (7.5 million hunters-gatherers were enough to cause ecosystem destructions and the biggest part of mega-fauna extinctions all over the Earth at the height of the Upper Paleolithic) and genetic burden accumulation, etc. However, each technology implies new menaces and respective dangers and risks caused by belated understanding. Their substance as a whole is not reducible to what humanity faced in the 20th century.

Thus, nuclear war risks have overshadowed a new unexpected menace that scarcely loomed up more than half a century ago: the lines between the conditions of peace and war started to blur. In our calculation, up to 25 million people died in the socalled "Cold" War, although we could register no more than four officially declared wars after 1945 and these were not the most large-scale or sanguinary ones (like the Honduras - Salvador "Football War" in 1969) [3]. Since the Nuremberg Trial condemned "war" as an outrage on humanity, most armed conflicts were accompanied by the inexhaustible euphemisms, sometimes rather absurd ones, like the "humanitarian bombardment" in Yugoslavia, 1999.

Since then, it has been more and more difficult to distinguish between war and peace, which was completed by the blurring lines between war and non-war techniques. The computer engineer, Bill Joy [37], noticed in 2000 that the weapon of mass destruction century was giving place to the century of knowledge-enabled destruction. Unlike the ballistic rockets and nuclear warheads, the newly developing technologies, every day cheaper and more available, are slipping out of governmental control and falling into the hands of irresponsible fanatics or of simply oafs.

Besides, after the bipolar world was destroyed in the 1990s, the state leaders' political thinking has been losing its quality as well. The grand masters of the 1950-80s have been replaced by lowergrade players without their predecessors' habit of estimating several moves ahead. The new leaders, therefore, are facing one boomerang effect after another on the international scene. Since the bipolar worldview conserved its dominance, this turned by a pathology of poles in the global geopolitics by the beginning of the new century. On one pole, we found the Western elites, still infected by the euphoria of "Cold War" victory and an irrational craving for new and new "small victorious wars" under the pretext of forced democracy spreading. The other pole, emptied after the USSR defeat, was filled by terrorist groups and gangs, the ones that had been cherished by the opposing military blocks in their time and then left alone by the bosses and thus grew wild. (Similar situations are well-known in ecology: for instance, after wolves are shot out, their niche is occupied by the feral dogs.)

The historical situation on the whole remains highly ambiguous. In 2003, the Royal astronomer of Great Britain Sir Martin Rees [38] appraised Earth civilization's chances to survive the 21 st century as 50:50, which corresponded to our own scenarios at that time. Indeed, the 2000s were marked by the historical record of nonviolence: the UN and the WHO data reflected an unprecedentedly low Bloodshed Ratio, so that the overall violent deaths in international, everyday conflicts and political repressions during the decade were yearly less than the number of suicides $[39,40]$. Yet, since 2011, further developments haven't followed the optimal 
scripts. A nuclear war is actually considerably less probable than it was in the 1950-60s, as far as humanity has adjusted to this menace. Yet in the developing technological and geopolitical situation, a global catastrophe can happen without a "world war" in its 20th century readings. Following Thomas Eliot's prophesy, we may grotesquely remark that the 20th century world could have ended with a "bang", while the 21 st century can end with a "whimper". Most people will hardly realize the transition to history's "descending branch" in any of the imaginable scenarios, like a sliding down to the medieval condition and further back.

Today even more than ever before, the principal menaces are rooted in human minds. What we are facing now is not a "clash of civilizations" but rather a clash of the historical époques concentrated in the planet civilization's unique space-time. The past is often taking revenge (a hundred years ago Walther Rathenau called it "vertical intervention of barbarism", cited from [41, p.9]), which now shows the appearance of the symptoms of the approaching history's "descending branch". Religions and confessional distinctions cause confrontations, and the political vocabulary is overfilled with anachronistic schemas like "national interests" or "national future".

Our polling shows that politicians and political scientists can neither distinguish between concepts like "interest", "ambition", "caprice" and "profit" nor define "nation" amidst the growing interfusion of races, languages and religions. Consequently, the ambition of a powerful political leader, a dominant mass emotion or an influential corporation's profit is marked as the national interest. In fact, the excess of emotionally overloaded words with empty contents devalues the "patriotic" rhetoric and makes the quality of political discourse dangerously out of tune with the developing technologies. According to our observations, most politicians and their counselors aren't aware of how absurd a "national destiny" beyond the world civilization's perspective is. Content-analysis of the leading statesmen's speeches shows an obsessive link between words like "union" or "consolidation" and the word against. The enemies' crafty designs are central in the political argumentation again as a reaction to the side effects of the rectilinear "globalization" utopia.

The menaces in this century are related to the inertia of ideological thinking, which is traditionally based on the "them-us" matrix. From time immemorial, the image of common enemy has been a significant factor in social worldview and solidarity. It relatively restricted violence inside a tribe, chiefdom, state, confession or class by transferring aggression outside; at once, it served as the meaning-formation guideline. Meanwhile, the ideologies that agitated peoples in the 20th century have lost their motivation; this also includes liberal democracy stripped of its Protestant background. As far as many people feel uncomfortable beyond the "them-us" mental pattern, a search for strategic meanings is reanimating religious and/or national fundamentalism.

\section{Life's Meaning: The Nucleus of 21st Century Global Problems}

The new paradigm is the incarnation of a
more optimistic view for the ones who are
searching for life's meanings.

Paul Davies

Social-psychological experiments [42] have demonstrated that there is at least one alternative mechanism for both consolidation and meaningformation: the image of common cause. This image doesn't assume an ill-intentioned enemy agent but rather aims at a joint work to overcome the natural chaos or the effects of humans' own thoughtlessness. We find it in the political experience as well: here, the grandiose compromises half a century ago should be remembered again. The great thinkers since the early Axial époque (about 2.5 thousand years ago) have been looking for the non-confrontational 
solidarity concept, so that cultural history brings us high standards of panhuman meanings beyond religious or quasi-religious ideologies. However, the masses' readiness to adopt such mental constructions has always been limited. Contrariwise, historical evidence is abundant that after a long period without real or potential wars, life's meanings dilute and the masses feel nostalgia for new demons and idols.

So far, besides being a resource for meaningformation, intergroup conflicts have been social development factors as well, including the advance in humanitarian values. Yet, given the pattern of delayed dysfunction (see above), present-day technologies make this historical inertia fraught with a possible planetary collapse. Thus, life's meanings have become the nucleus of the 21 st century global agenda. More specifically, the issue is about whether or not our minds prove ready to construct strategic meanings beyond ideologies and intergroup confrontations.

The fantastic époque we are living in has made all of the previous époques' material deficits potentially surmountable by the developing technologies: hunger and other vital discommodities are in modern world not so much due to the absence of products as to factors like war, blockade or overwhelming corruption. So more pressing has become the deficit of unifying meanings and values. To afford one more grotesque allegory, I would say that Cosmos is an inexhaustible source for such ones, and Big History may serve as an instrument for their abstraction. Indeed, although classical science was in its essence indifferent to human aims, values, meanings or destinies, these categories are essential in modern cross-disciplinary knowledge. Therefore, systematic outreach and awareness-raising may help develop planetary and cosmopolitan consciousness among both civil society and political leaders (by considering their professional properties).

This is the background for our practical recommendations.

\section{Recommendations}

While considering any event, let us ask ourselves how it might be useful in the following order:

1 for humankind,

2 for the motherland, 3 for one's friends and family,

4 for oneself.

The origin of all of the evils that surround us from the cradle is our manner to turn this progression backward.

Vladimir Odoyevsky

Scientists in various countries have lately been discussing calculations and respective hypotheses of the planetary Singularity. International meetings have been held and monographs and collections of papers published. The Singularity University (SU) started to function in the Silicon Valley in 2009 under the aegis of NASA and other organizations. The Center for Mega-History and System Forecasting (CMHSF) was founded in 2010 in the Institute of Oriental Studies, Russian Academy of Sciences. Similar institutions have been later formed in Japan and in some post-Soviet countries. In 2010 the International Big History Association (IBHA) was established from networking in the World History Association (WHA). Even earlier, since the early 2000s, respective cross-faculty courses have been taught in the universities of Europe, America, Asia and Australia, which gather hundreds of students in the lecture halls. Unfortunately, the two research lines the one studying more the future and the other mostly turned to the past - are so far faintly connected. Still more lamentable is the fact that the relevant scientific discoveries have not yet attracted attention of either professional politicians or politically active citizens, though competently organized presentation might considerably influence many people's thinking and activities. 
Our basic suggestion is to launch an international program for extending the web of clubs and public universities in order to discuss popularly global scenarios and to demonstrate humanity's inseparable destiny in the observable future. The job might be done under the aegis of the Global Challenges Foundation and other humanitarian institutions, including UNESCO. If the suggestion excites the experts' interest, the CMHSF in contact with IBHA and SU might gather an international cross-disciplinary professional group to prepare particular syllabi, learner's guides, audio-visual and other aids for popular cosmopolitan education. A relevant set of films, gaming and other artworks has been accumulated by the professional communities for more than fifteen years. Mass media, Internetresources and opinion leaders in the informal webs and the mass and network communication psychological technologies are to be involved as well. The experience of teaching Mega-history (Big history), global prognostication and psychology of social security in various universities are to be synthesized at the preparatory stage. It goes without saying that the syllabi, didactic aids and methodic are supposed to be adapted to the audiences' cultural and religious traditions, educational attainments and professional interests. The standard syllabus might include the following subject directory.

\section{1}

The first subject scope gives elementary information about Mega-history. The teacher is to show graphically how the continual evolution of cosmos, Earthly nature and humankind has been lined up in a single, actually and potentially interdependent process. It is useful to demonstrate to what extent human body and mind, from the elementary reactions up to the most complex conceptual constructs, are related to our cosmic origin and to the evolution of life and culture.

\section{2}

The second subject scope includes a review of human history and prehistory emphasizing the dramatic relationship between the developments in technological and humanitarian culture. It should be shown how any new military or production technology entailed both privileges and menaces, what kind of catastrophes the misbalances between technological powers, on the one hand, and cultural and psychological self-control on the other, entailed, and how the advances in values and norms have provided societies' sustainability in spite of the growing destructive power of their technologies. Here, the story of the birth, evolutions, inner splits and compromises of the world religions, nations, and classes would be appropriate.

Great thinkers' and prophets' insights should be recounted, those that refer to the panhuman solidarity without group-versus-group confrontation, like the one by the 19th century Russian "Cosmist" philosopher in the epigraph; there are similar examples in many cultural traditions. Besides, it is high time to demonstrate to students and the general public why and how the role of individual decisions and actions in world causalities has been growing with the technological power.

To develop this subject scope, we suggest using the conception of anthroposphere as an antithesis to the bio-centric philosophy ("humans are an element of the biosphere"), which was very popular in the second half of the 20th century. That philosophy essentially promoted ecological consciousness, but later on it led its adherents into the deadlock of misanthropy. Anthroposphere is the background of the ecological philosophy in the 21 st century. It is seen as a radically more complex system (compared to the pre-human biosphere) in which biota constitute the bearing substructure, and its control unit is human mind. Social-natural system's sustainability depends more and more on the conditions of the public consciousness, and the internal contradictions and disparities in its development are the chief reasons 
for natural and social calamities, which now threaten with the Earth evolution's breakup.

\section{3}

The third subject scope refers to the prognostic tree. Here, it is particularly important to take into account the disputants' educational attainment, qualification and prevailing values. Subject to these qualities, up-to-date calculations and data from the sciences and the humanities should be presented to demonstrate how absurd and utopian are the "separate" futures for the national or confessional communities.

Specific experiments and trainings will demonstrate how both human solidarity and strategic life's meanings are possible based on a cosmic perspective of the intelligence that has originated from Earthly humans development, without either the "them-us" contrapositions or the appeals to a Heavenly Lord. While working with mature and especially young politicians, it is worth appealing to their professional ambitions. The trainer needs to show them how those who first exploit the evidences of the next decades' crucial moment for world history in their programs and arguments beyond "national interests" and similar archaic stereotypes can gain determinant advantage and international public support.

The crisis of the simplified versions of "Globalization" requires particular discussion. The interventions of "advanced" states and governments in the "behindhand" peoples' life, on the one hand, and mass migrations into the richer regions, on the other hand, call forth growing protests both from the "left" and the "right". It seems important to show that what provoke uncontrolled mass migrations and sudden collisions among different historical époques with resulting cultural shock are, in most cases, just poorly thought-out interventions, including the military ones. Taking into account that globalization is the imperative for the modern world's survival, collective compromise programs are necessary; otherwise, the conflicts will most probably multiply.

Conceptually, this may also be supported by the synergetic system theory which supplements the Law of requisite variety by the Law of hierarchical compensations. The latter is as highly universal as the former one; it claims that the increase in a hierarchical system's aggregate variety results from the restriction of variety (unification) at its lower levels, and vice versa - the increase in variety at the lower level destroys the upper levels of the organization. In our case, subsequent social systems complication implies the growth of micro-group and individual varieties at the expense of diffusing macro-group (national, confessional or class) distinctions with commonly accepted panhuman values and norms.

Advisory support should be presented for Western politicians to form electoral programs and technologies that might be attractive for civil society and essentially increase their political effect. Work with "non-Western" politicians will require still more careful aid of competent analysts and opinion leaders.

In our tentative estimates, in case of the intensive involvement, the first organizational stage would take near half a year. Taking into account further approbation and corrections, the systematic campaign of full value might start a year later.

\section{References:}

1. Taleb N.N. (2016) The "Long Peace" Is a Statistical Illusion. http://www. fooledbyrandomness.com/pinker.pdf

2. Merton R.K. Social Theory and Social Structure. N.Y.: Free Press, 1968.

3. Nazaretyan A.P. (2017) Non-Linear Futures: Mega-History, Complexity Theory, Anthropology \& Psychology for Global Forecasting. 4th ed. Moscow: Argamak-Media (In Russian).

4. Jantsch E. (1980) The Self-Organizing Universe. Scientific and Human Implications of the Emerging Paradigm of Evolution. N.Y.: Pergamon Press.

5. Moiseev N.N. (1991) Universal Evolutionism: Position and Corollaries // Problems of Philosophy, \#3: 3-28 (In Russian).

6. Nazaretyan A.P. (1991) Intelligence in the 
Universe: Origin, Formation and Perspectives.

Moscow: Nedra. (In Russian).

7. Christian D. (1991) The Case for 'Big History' // Journal of World History 2 (2): 223-238.

8. Christian D. (2004) Maps of Time: An Introduction to Big History. Berkeley: Calif.: Univ. of California Press.

9. Chaisson E.J. (2005) Cosmic Evolution: Synthesizing Evolution, Energy, and Ethics // Phylosophy \& Science (Russian Philosophical Journal), №5: 92-105.

10. Nazaretyan A.P. (2005) Western and Russian Traditions in Big History: A Philosophical Insight // Journal for General Philosophy of Science, 36: 63-80.

11. Spier F. (1996) The Structure of Big history. From the Big Bang until Today. Amsterdam: Amsterdam University Press.

12 Grinin,. L.E., A.V. Korotayev, B.H. Rodrigue (eds.). (2015/2017). From Big Bang to Global Civilization: A Big History Anthology In 3 volumes. Delhi: Primus Books.

13. Nakanishi, Osamu (chief ed.) Universal Studies and the Modern World. Becoming Global and Cosmic Humanity. Yokohama: Institute for Global and Cosmic Peace, 2017.

14. Rozanov A.Yu. (2009) Life Conditions on early Earth After 4.0 Billion Years Ago // Problems of the Origins of Life. Moscow: Institute of Paleontology: 185-201 (In Russian).

15. Tyson N.DeGrass, Goldsmith D. Origins. Fourteen Billion Years of Cosmic Evolution. N-Y, London: W.W. Norton \& Co, 2014.

16. Panov A.D. (2005) Scaling Law of the Biological Evolution and the Hypothesis of the SelfConsistent Galaxy Origin of Life // Advances in Space Research, 36: 220-225.

17. Snooks G.D. The Dynamic Society. Exploring the Sources of Global Change. London and N.Y.: Routledge, 1996.

18. Panov A.D. Completion of the Planetary Cycle of Evolution? // Philosophy \& Science, 2005, \#3-4: 42-49, 31-50 (In Russian). 19. Kurzweil R. (2005) The Singularity Is Near: When Humans Transcend
Biology. N.Y.: PB.

20. Eden, A.H., J.H. Moor, J.H. Søraker and E.

Steinhart (eds.). (2012) Singularity Hypotheses. A Scientific and Philosophical Assessment Berlin Heidelberg: Springer-Verlag.

21. Nazaretyan A.P. (2016) Non-Linear Futures: The "Mysterious Singularity" in View of Mega-History // Between Past Orthodoxies and the Future of Globalization. Contemporary Philosophical Problems. Boston: Brill-Rodopi: 171-191.

22. Weinberg S. (1993) The First Three Minutes: A Modern View of the Origin of the Universe. N.Y.: Basic Books. 23. Deutsch D. (1997) The Fabric of Reality. London, N.Y.: Allen Lane, The Penguin Press.

24. Rees M. (1997) Before the Beginning. Our Universe and Others. N.Y.: Helix Books.

25. Davies P. (2004) The Cosmic Blueprint: New Discoveries in Nature's Creative Ability to Order the Universe. Philadelphia \& London: Templeton Press.

26. Smolin Lee (2014) The Singular Universe and the Reality of Time: A Proposal in Natural Philosophy. Cambridge: Cambridge Univ. Press.

27. Duncker K. (1935) Zur Psychologie des produktiven. Denkens. Berlin: Springer.

28. Kaku M. (2014) The Future of the Mind: The Scientific Quest to Understand, Enhance, and Empower the Mind. N.Y. etc.: Doubleday.

29. Elias N. (1939/2000) The Civilizing Process:

Sociogenetic and Psychogenetic Investigations.

Rev. ed. Cambridge, Mass: Blackwell.

30. Gurr T.R. (1981) Historical Trends in Violent

Crime: A Critical Review of the Evidence // Crime \& Justice: An annual Review of Research, 3(29): 295-353.

31. Cockburn J.S. (1991) Patterns of Violence in English Society: Homicide in Kent, 1560-1985 // Past \& Present, 130: 70-106.

32. Keeley L.H. (1996) War before Civilization.

The Myth of the Peaceful Savage. N.Y.: Oxford University Press.

33. Eisner M. (2003) Long-Term Historical Trend in Violent Crime // Crime \& Justice, 30: 83-142. 
34. Nazaretyan A.P. (2010) Virtualization of Social Violence: A Sign of Our Époque? // Societal and Political Psychology International Review, 1, \#2: 23-36.

35. Nazaretyan A.P. (2009) Technology, Psychology and Catastrophes: On the Evolution of NonViolence in Human History // Social Evolution \& History, VIII, \#2, p.102-132.

36. Pinker S. (2011) The Better Angels of Our Nature. The Decline of Violence in History and Its Causes. N.Y.: Viking Penguin.

37. Joy B. (2000) Why the Future Doesn't Need Us? // Wired, April: 238-262.

38. Rees M.J. (2003) Our Final Century: Will the Human Race Survive the Twenty First Century? N.Y.: Basic Books.

39. Krug E.G., Dahlberg L.L., Mercy J.A., Zwi

A.B. and Lozano R. Eds. (2002) World Report on Violence and Health. Geneva: World Health Organization.

40. Global Study of Homicide. Trends, Contexts, Data. UNODC, 2011.

41. Mosionzhnik L.A. (2012) Technology of

Historical Myth. Saint Petersburg: Nestor-Istoria. (In Russian).

42. Sherif M., Harvey O.J., White B.J., Hood W.R. and Sherif C.W. (1961) Intergroup Conflict and Cooperation: The Robber's Cave Experiment. Norma, Oklahoma: Univ. of Oklahoma Press. 
